\section{This month in JICS}

\author{
Jonathan M Handy
}

lournal of the Intensive Care Society 2015, Vol. 16(4) 277

(C) The Intensive Care Society 2015 Reprints and permissions: sagepub.co.uk/ journalsPermissions.nav DOI: $10.1177 / 1751143715607733$ jics.sagepub.com

SSAGE
Welcome to another issue of JICS which, I hope, will sustain you through the long nights as we head into the festive season; and, as sure as the changing of the seasons, further change is upon us within the NHS. Evolution and adaptation are necessary in health care provision in order for the systems in which we work to provide adequately for a population with changing technology, infrastructure and expectations. However, not all change is welcome and some come about through unintended consequences. In my own hospital, an example of this is the increasing trend to involve intensivists in all decisions regarding escalation of care and, increasingly, in do-not-attemptresuscitation orders. As a result, the traditional model of one intensive care consultant being on-call for the whole hospital is being challenged. For one individual to review, discuss and assist with such decisions requires significant periods off the intensive care unit (ICU) with a subsequent decrease in time available to deliver care, support trainees and other ICU staff, speak with relatives, and supervise the care of the hospital's sickest patients. That our expertise is being sought with increasing frequency is hardly surprising, and it will likely lead to improved decision making with regard to escalation of care, and communication with patients and their loved ones. However, this model of care puts an additional strain on an already stressed ICU environment and needs to be recognised and supported. Speaking with ICU colleagues further afield has identified that I am not alone and that many are experiencing similar issues; indeed, there is increasing evidence of hospitals adopting a second ICU consultant onto a daytime (often weekday only) roster in order to deal exclusively with the 'off-unit' issues. This poses both manpower and financial resource issues for our profession, and I would welcome feedback on whether this is perceived as a wider problem to be addressed.

In true JICS style, this issue brings a variety of articles for your stimulation, interest and, I hope, enjoyment. In the opening editorial, Adrian Wong provides a thought-provoking examination of the role of autopsies on critically ill patients in modern healthcare. His analysis highlights the decreasing number of autopsies being undertaken and the implication that this has on both diagnostic certainties and research opportunities. He concludes that improved training and focus on consent for autopsies would be of benefit to our profession, a view with which I firmly agree, though it will be interesting to see how this sits within our society's current expectations.

Also in this issue, Tim Walsh and Steve Brett report on the national stakeholder meeting which met to consider the priorities for future success in UK critical care research. This, together with the James Lind Alliance Priority Setting Partnership findings ${ }^{1}$ provide a detailed 'road-map' to guide future research for UK critical care. Original articles include the investigation of the effects of mal-positioned tracheostomy tubes on flow and resistance, and a focus on faecal incontinence and its management in critically ill patients. Jon Rivers and colleagues provide an innovative yet simple approach to calculating the ideal tidal volumes for ventilated patients in the ICU. Their 'cut out and keep' solution provides a formula that is easily distributed and implemented; a 'quick win' for any unit choosing to adopt it. We have a variety of articles covering topics including haemophagocytic syndrome in the ICU, chest drain management, chest radiograph interpretation, druginduced hyperthermia, and acute central nervous system infections; a basic science/translational slant is provided by Thomas Morrison and colleagues in their article focusing on mesenchymal stromal cells as an exciting potential therapy for acute respiratory distress syndrome.

Together with our CAT reviews, case reports and correspondence (plus a contribution from Lemmingaid), I hope this issue will provide something to stimulate and educate through to the New Year! As always, my sincere thanks to all who have contributed in bringing this issue to fruition and, while it seems rather early to get too festive, being the last issue of 2015 I wish you all the very best through the festive season and New Year.

\section{Reference}

1. Reay H, Arulkumaran N, and Brett SJ. Priorities for future intensive care research in the UK: results of a James Lind Alliance Priority Setting Partnership. JICS 2014; 15: 288-296.

Editor-in-Chief

Corresponding author:

Jonathan M Handy, Imperial College London, London, UK. Email: j.m.handy@imperial.ac.uk 